\title{
Critical features of peer assessment of clinical performance to enhance adherence to a low back pain guideline for physical therapists: a mixed methods design
}

\author{
Marjo J. M. Maas ${ }^{1,2^{*}}$, Simone A. van Dulmen², Margaretha H. Sagasser ${ }^{3}$, Yvonne F. Heerkens $^{1,4}$,
} Cees P. M. van der Vleuten ${ }^{5}$, Maria W. G. Nijhuis-van der Sanden ${ }^{2}$ and Philip J. van der Wees ${ }^{2}$

\begin{abstract}
Background: Clinical practice guidelines are intended to improve the process and outcomes of patient care. However, their implementation remains a challenge. We designed an implementation strategy, based on peer assessment (PA) focusing on barriers to change in physical therapy care. A previously published randomized controlled trial showed that PA was more effective than the usual strategy "case discussion" in improving adherence to a low back pain guideline. Peer assessment aims to enhance knowledge, communication, and hands-on clinical skills consistent with guideline recommendations. Participants observed and evaluated clinical performance on the spot in a role-play simulating clinical practice. Participants performed three roles: physical therapist, assessor, and patient. This study explored the critical features of the PA program that contributed to improved guideline adherence in the perception of participants.
\end{abstract}

Methods: Dutch physical therapists working in primary care $(n=49)$ organized in communities of practice $(n=6)$ participated in the PA program. By unpacking the program we identified three main tasks and eleven subtasks. After the program was finished, a questionnaire was administered in which participants were asked to rank the program tasks from high to low learning value and to describe their impact on performance improvement. Overall ranking results were calculated. Additional semi-structured interviews were conducted to elaborate on the questionnaires results and were transcribed verbatim. Questionnaires comments and interview transcripts were analyzed using template analysis.

Results: Program tasks related to performance in the therapist role were perceived to have the highest impact on learning, although task perceptions varied from challenging to threatening. Perceptions were affected by the roleplay format and the time schedule. Learning outcomes were awareness of performance, improved attitudes towards the guideline, and increased self-efficacy beliefs in managing patients with low back pain. Learning was facilitated by psychological safety and the quality of feedback.

Conclusion: The effectiveness of PA can be attributed to the structured and performance-based design of the program. Participants showed a strong cognitive and emotional commitment to performing the physical therapist role. That might have contributed to an increased awareness of strength and weakness in clinical performance and a motivation to change routine practice.

Keywords: Peer assessment, Peer review, Guideline adherence, Knowledge translation, Performance assessment

\footnotetext{
* Correspondence: marjo.maas@han.nl

${ }^{1}$ HAN University of Applied Sciences, Institute for Health Studies, Kapittelweg

33, 5425 EN Nijmegen, The Netherlands

${ }^{2}$ Radboud University Medical Center, Institute for Health Sciences, IQ

healthcare, Geert Grooteplein 21, 6525 EZ Nijmegen, The Netherlands

Full list of author information is available at the end of the article
} 


\section{Background}

Clinical practice guidelines are intended to optimize patient care and improve patient outcomes [1]. Guidelines are also increasingly regarded as a part of professional quality systems and policies [2]. However, the uptake of guidelines in physical therapy (PT) practice remains a challenge, despite the variety of implementation strategies that have been developed [3-5]. Professionals are hampered by a lack of commitment to the guidelines, insufficient knowledge and skills related to the guidelines, and limited social and organizational support [6-8]. In addition, a study by Rutten et al. [9] on determinants of guideline adherence showed that physical therapists (PTs) do not hold realistic perceptions of the extent to which they adhere to guideline recommendations.

The limited ability of clinicians to accurately selfassess the quality of their professional performance is not new [10]. A compelling body of research evidence shows that the development of adequate self-perception requires both internal and external information about one's professional performance, including appropriate performance standards [11-15]. There is a need for interventions containing feedback that can help to develop realistic self-perceptions of guideline adherent behavior and enhance motivation to change routine practice.

We designed an implementation strategy based on peer assessment (PA) that targets identified barriers to change for PTs in primary care [16]. We tailored an existing PA design that was shown to be effective in undergraduate PT education [17] to the context of professional PT practice and to the purpose of guideline implementation. In a previously published randomizedcontrolled trial (Table 1), PA was shown to be more effective than the traditional "case discussion" implementation strategy [18]. We analyzed this PA program to determine the critical features of its success.

In PA professionals evaluate or are being evaluated by observing their peers in a role-play that simulates PT practice. They provide each other with performance feedback that might evoke reflection and identify areas of clinical performance that need improvement $[19,20]$. Personal assumptions about one's professional competence can be compared with peer views that might compensate for poor self-assessment $[13,14]$. Peer assessment enhances the development of a mutually accepted quality standard of performance by introducing peers to an "assessor" or "auditor" perspective $[23,26]$. In this respect, PA might be a an effective tool to enhance bottom up quality improvement and accountability of health care [21, 22].

Research shows that effective peer assessment practices are context-specific and culture dependent [23, 24], and these findings also apply to effective implementation strategies [25]. Thus, to enhance the generalizability of
Table 1 Overview of the methods and results of a previously published trial (Van Dulmen et al. [18])

\section{Design}

A cluster-randomized controlled trial was conducted among 10 communities of practice (CoPs) of Dutch physical therapists $(n=90)$ to compare the effectiveness of two implementation strategies: peer assessment (PA) and case discussion (CD). Both strategies aimed to improve adherence to the clinical practice guidelines for the management of patients with low back pain. The programs consisted of four meetings over a six-month period. Outcomes were measured at baseline and at 6 months follow up.

Randomization and intervention allocation

CoPs showing interest in the program were invited to a plenary meeting in November 2009. They were informed that the study compared two educational strategies, and that both programs required an equal amount of time and effort. All physical therapists regularly treating patients with low back pain were eligible for inclusion. Included CoPs were randomly allocated to the PA group and the CD group resulting in six CoPs for the PA program $(n=49)$ and four CoPs for the CD program $(n=41)$.

\section{Interventions}

PA is the process whereby professionals evaluate or are being evaluated by their peers and provide each other with performance feedback. The main difference between PA and CD is that in the PA approach the tasks were structured, with a focus on performance rather than discussion, and participant roles were pre-defined. In the CD approach the tasks were less structured with ample opportunity for in-depth elaboration and discussion, and participant roles were not defined. In PA and $C D$, participants worked on identical cases concerning problem content, but for PA these cases were adjusted to allow for performance of participants in different roles. In PA, written cases were not known in advance but were presented by a coach on the spot, simulating daily clinical practice. For CD groups, written cases were included in the program guide to allow for proper preparation, along with instructions and written questions to guide the discussion process.

\section{Outcome measures}

Outcomes were assessed at baseline and at six months. Primary outcome was knowledge and guideline-consistent reasoning, measured with 12 performance indicators using four vignettes that fully covered the patient profiles described in the guidelines. Changes in reflective practice were measured with the Self-Reflection and Insight Scale (Grant et al., [49]).

Results

Vignettes were completed by 78 participants (PA group $n=44 ; C D$ group $n=34$ ). Multilevel analysis showed an increase in guideline-consistent clinical reasoning of $8.4 \%$ in the peer-assessment groups whereas the control groups showed a decline of $0.1 \%$ (estimated group difference $8.7 \%$; $95 \%$ Cl: 3.9 to $13.4 ; P<0.001)$. No group differences were found for self-reflection.

the trial results, and to allow for adequate knowledge transfer, understanding of the causal mechanisms of PA is necessary [25-27].

The aim of this study was to explore the features of the PA program that were perceived to have a powerful impact on learning and change of routine practice.

Our research question was:

Which elements of the PA program were perceived to have a strong impact on clinical performance 
improvement consistent with clinical guidelines, and why?

\section{Methods}

\section{Study design}

We conducted a mixed-methods study using questionnaires and semi-structured interviews to explore the critical features of the PA program that contributed to improved guideline adherence.

\section{Setting and participants}

The Royal Dutch Society for Physical Therapy offers annual professional development programs for the approximately 800 communities of practice in the Netherlands. Communities of practice are small groups of 5-15 PTs who share the same setting or the same interests. The current study focused on communities of practice $(n=6 ; 49$ participants) that participated in a randomized controlled trial (Table 1) and were allocated to the PA-condition.

\section{The peer assessment program}

The PA program was launched in February 2010 and finished in September 2010. Its design was built on a mix of theoretical constructs related to learning and professional behavior change, which were assumed to contribute to improved clinical performance [26]. Table 2 shows the theoretical framework, the underlying constructs, and the operationalization of these constructs in the PA design.

The PA program aimed to enhance clinical performance consistent with guideline recommendations including knowledge, communication, and hands-on clinical skills. Clinical performance was directly observed and evaluated by peers in a role-play that simulated clinical practice. Participants received a PA-manual in advance, containing a description of the PAprocedure, a time schedule for each meeting, and guidelines for receiving and providing constructive feedback. They received a link to the updated guideline "Low back pain for physical therapy and manual therapy" (Staal et al. [28]) published by the Royal Dutch Society for Physical Therapy. Four meetings were scheduled over a period of six months. As the PTs were novices in the PA method, and no additional training was provided, the PA process was supported by a coach (MM or HE). Coaches were experienced PTs, teachers in PT education, and trained in the PA procedure. They facilitated the process of providing and receiving feedback, and they gave additional feedback when needed.

Table 2 Theoretical framework of the PA program design

\begin{tabular}{ll}
\hline Theory & Underlying constructs used \\
\hline Social constructivist & Contextual learning, collaborative learning, \\
learning theory [48] & $\begin{array}{l}\text { active participation, and knowledge construction } \\
\text { to enhance attention, storage, and retrieval of } \\
\text { knowledge from memory. }\end{array}$
\end{tabular}

Self-regulated learning theory $[50,51]$

$\begin{array}{ll} & \begin{array}{l}\text { Self-assessment } \\ \text { Conscious goal setting and action planning }\end{array} \\ \text { Situated learning } & \begin{array}{l}\text { Learning in the context of daily practice to bridge the } \\ \text { theory [40,52] }\end{array} \\ \text { gap between learning context and application context. } \\ \text { learning theory [33] } & \begin{array}{l}\text { Enhancing the development of self-efficacy beliefs. } \\ \text { Performing the new behavior and experiencing the }\end{array}\end{array}$

Observing the behavior of others and the consequences of that behavior (vicarious experience).

Stages of change Alligning implementation strategies to the stages of theory [53] change.
Changing attitudes and subjective norms toward the new behavior.

Enhancing the development of self-effecacy beliefs.

Operationalization of constructs

Presenting a variety of clinical problems that adequately reflect authentic clinical practice, accounting for the case-specifity of clinical competence.

Simulating the context of daily practice in a role-play accounting for the context-specifity of clinical competence.

Enhancing active participation of each participant by assigning pre-defined roles, and by using a performance based format.

Designing an improvement plan based on peer feedback.

Discussing the improvement plan with peers.

Delivering the program within communities of practice that share the same setting or the same interest.

Performing the new behavior individually, by reasoning aloud and demonstrating diagnostic and treatment skills relevant to the LBP guidelines.

Observing a peer's performance and providing individualized improvement feedback.

Delivering the program within communities of practice. Peers are involved in the professional development process and are capable of tailoring feedback to stages of change.

Introducing peers to the assessor perspective. In appraising a peers' performance, peer assessors need to develop an understanding and a mutually accepted quality standard to deliver credible performance feedback. 
Each participant performed three roles: PT, assessor and simulated patient. In the PT role, participants completed a written assignment that contained a clinical case and brief instructions for diagnosis or treatment. Clinical cases were developed by a team of experienced PTs and guideline experts. The cases fully covered the patient profiles of LBP described in the guidelines, including red flags. PTs analyzed the clinical cases by reasoning aloud and demonstrated (hands-on) skills relevant to the clinical problem. Afterwards, they reflected on their performance. In the assessor role, peer performance was observed and assessed with a scoring sheet containing performance criteria that could be scored on a 7-point scale $(1=$ much improvement needed, to $7=$ no improvement needed) and space for written feedback. Performance categories addressed diagnosis, treatment, and evaluation. In the patient role, participants received the clinical case along with written simulation instructions. Simulation instructions consisted of a description of the patient's complaints, including personal factors (e.g., cognitive / emotional), and contextual factors (e.g. family, work) that might be relevant to the patient's problem. Participants were instructed to improvise patient responses and provide feedback from the patient perspective.

Prior to the third session, each participant developed a personal change plan, including an action plan, based on performance feedback and self-assessment. In the third meeting, the group reviewed change plans and provided additional peer feedback. The fourth session was identical to the first two sessions, but the design of the clinical cases was tailored to participants' specific learning needs.

\section{Questionnaires and interviews}

Prior to data collection, we unpacked the PA program and identified three main tasks and eleven subtasks that were assumed to affect guideline adherence. Task analysis was supported by guidelines described by Janssen-Noordman et al. [29]. An online questionnaire was administered after completion of the PA program in which participants were asked to rank the program tasks from high to low learning value, assigning the highest rank for the most learning value and the lowest rank for the least. Subsequently, they were asked to provide written comments on the three most instructive PA task elements (Additional file 1).

Emerging questions from the questionnaires comments served as input for conducting semi-structured interviews to obtain more understanding of how the PA program affected professional development (Additional file 2). In contrast to a reductionist approach to the data by means of task analysis and task ranking, the interviews had a more holistic approach, focusing on experiences with the PA program as an integrated system. From each peer group, one PT was selected for an interview $(n=6)$. Purposeful selection was based on average and deviant ranking results. An interview guide was designed by $\mathrm{MM}$ and PW addressing the three main questions that emerged from the questionnaire data:

1) What did you expect of the PA program?

2) How did you perceive the PA program, and how did it affect your daily practice?

3) In the questionnaire, you indicated that you perceived task $\mathrm{X}, \mathrm{Y}$ and $\mathrm{Z}$ to have the strongest learning value. Can you explain why?

Selected participants were invited by e-mail, and received information about the study's purpose, procedure, the use of the data, and the focus of the interview.

The first interview was conducted by MM and PW face-to-face. The following interviews were conducted by either MM or PW using teleconferencing technology. To enhance the credibility of the results, research assistants AS and GB joined the telephone interviews, taking notes and posing additional questions when needed. Interviews of each participant, including verbal consent, were audiotaped. Interviews lasted between 45 and 90 minutes. Recordings were transcribed verbatim. An independent check on the transcripts was conducted by $\mathrm{AS}$ and $\mathrm{GB}$.

\section{Data analysis}

\section{Quantitative analysis}

Ranking results were described by calculating mean, median, and sum scores for each learning task using IBM SPSS statistics 20.

\section{Qualitative analyses}

A sample of texts from questionnaires and interview transcripts was studied and coded by MM and PW independently. The analytic process was guided by template analysis that combines a-priori codes with emerging codes [30]. The PA program as a whole and its learning tasks and subtasks served as a-priori codes. Additional codes were defined during the analytic process when these seemed relevant regarding the research question. Codes were compared, and some codes were merged into higher-order codes. PW and MM discussed a codebook until consensus was reached. Subsequently, all written comments in the questionnaires and interview transcripts were analyzed line-by-line, using ATLAS-ti v.7 software. Emerging themes were identified by constant comparison of codes and higher order codes. We summarized the results in a matrix that crossed a-priori 
codes (tasks and subtasks) and emerging themes from the data [31]. Two independent researchers SD (health scientist and PT) and MS (educational scientist) evaluated the analysis process and outcomes. They were not involved in the design or delivery of the PA program. Disagreements were discussed until consensus was reached and we finally agreed that the matrix fully fitted the data.

\section{Ethical aspects}

This project received approval of the medical ethical committee of Radboud University Medical Center. All participants volunteered to participate and gave their informed consent. We adhered to the RATS guidelines for qualitative research [32].

\section{Results}

In total, 44 PTs have finished the program. Table 3 shows an overview of the participants' characteristics. Two PTs did not fully complete the ranking procedure and were excluded from quantitative analyses (response rate $=86 \%$ ). All PTs invited for additional interviews $(n=6)$ agreed to participate.

\section{Results quantitative analysis}

Ranking results showed that participants committed the most to subtasks related to task performance in the PT role. Receiving peer feedback was perceived as the most valuable element, followed by receiving external coach feedback, performing the clinical task individually, and receiving simulated patient feedback. Participants varied widely in their preferences for learning in the PT role, but agreed on the superior value of receiving peer feedback. Table 4 shows an overview of the results.

\section{Results qualitative analysis}

Five themes emerged from the analysis of the questionnaires comments and the additional interview

Table 3 Peer assessment group characteristics

\begin{tabular}{ll}
\hline Physical therapist characteristics & $N=44$ \\
\hline Age mean (SD) & $40.4(12.4)$ \\
Sex (male/female) & $17 / 27$ \\
Working hours per week (SD) & $32.5(9.6)$ \\
Treatment of patients with LBP per year & \\
$<25$ & 12 \\
$25-50$ & 12 \\
$50-75$ & 6 \\
$76-100$ & 5 \\
$>100$ & 10 \\
Manual therapist & 8 \\
Years of experience (SD) & $16.5(11.9)$ \\
\hline
\end{tabular}

transcripts. These themes were related to the PA program either as a whole, or related to its specific learning tasks and subtasks: a) general perceptions of the PA program, b) determinants of PA affecting perceptions, c) facilitators for learning, d) learning activities, and e) learning outcomes.

We summarized the results by creating a matrix that crossed a-priori categories (program tasks and subtasks) with emerging themes, leaving empty fields where data were not available (Table 5). Program tasks and subtasks in the matrix follow the build-up of the PA program. In the next section, we first discuss the general perceptions of the PA program, determinants of PA affecting these perceptions, and the general outcomes. Second, we discuss the subtasks by following the matrix, including their related learning activities, outcomes, and facilitators for learning. Although we did not explicitly ask participants to comment on tasks that were perceived as less instructive, they often did so spontaneously:

"Receiving feedback from your colleagues provides new insights. You learn from the mistakes you make, or how you can handle them better. I assigned the lowest ranks to 'receiving and providing scores' because I think that scores add nothing to the learning process. Moreover not all aspects of performance can be expressed in scores and scores are not objective" (Q-P8).

We limit the discussion to comments on the most instructive subtasks. Participants' quotes are coded by information source (Questionnaire $=\mathrm{Q}$; Interview Transcript $=$ IT) and by participant number (P1 - P42) (Table 5).

\section{The PA program as a whole General perceptions}

Participants were generally satisfied with the program. They reported that the mix of written cases adequately reflected the problems encountered in daily practice, however, the PA format was new, and was perceived with mixed feelings. Physical therapists were not used to exposing their professional performance for group review. Some participants appraised the PA program as challenging, providing an excellent opportunity to receive performance feedback; others were reluctant to expose their professional competence, triggered by feelings of performance anxiety.

Specific task features (time schedule and role-play format) affected perceived learning opportunities and threats. Participants, who appreciated the task structure, reported that PA allowed them to solve a considerable number of clinical cases in a relatively short time and trained them to be concrete and concise in reasoning aloud in the PT role as well as in the assessor role. 
Table 4 Results quantitative analysis

\begin{tabular}{|c|c|c|c|c|c|}
\hline Tasks & Subtasks & Mean & Median & Range & Sum \\
\hline Study manual & Study PA procedure and guidelines & 5.09 & 6.0 & 10 & 195 \\
\hline \multirow[t]{5}{*}{ Perform in PT role } & Perform clinical task individually & 8.05 & 9.0 & 10 & 322 \\
\hline & Receive peer feedback & 9.75 & 10.0 & 6 & 389 \\
\hline & Receive external coach feedback & 8.48 & 9.0 & 10 & 331 \\
\hline & Receive simulated patient feedback & 6.84 & 7.0 & 9 & 253 \\
\hline & Receive written feedback and scores & 2.91 & 2.0 & 9 & 102 \\
\hline \multirow[t]{3}{*}{ Perform in assessor role } & Observe peer performance & 6.46 & 6.0 & 9 & 252 \\
\hline & Provide oral feedback & 5.75 & 5.5 & 9 & 230 \\
\hline & Provide written feedback and scores & 2.58 & 2.0 & 4 & 44 \\
\hline Design change plan & Design and discuss change plan & 6.38 & 6.00 & 10 & 249 \\
\hline Perform in patient role & Simulate patient problem & 3.26 & 3.0 & 7 & 98 \\
\hline
\end{tabular}

"The strongest feature of PA was the structure of the meetings. The system of PA was interesting...for example, I appreciated that repeating feedback that was provided by someone else, was not allowed. It's useless to repeat advice."(IT-P41)

Participants who criticized the task structure perceived the timetable as stressful, and as a barrier to in-depth case discussion.

"Yes, time pressure was a weakness of PA....sometimes the performance evaluation raised questions which could not be addressed in-depth, because you had to skip to a new problem. I would prefer to perhaps discuss fewer cases more extensively".(IT-P18)

From the perspective of the assessor, the role-play was appreciated because it allowed implicit behaviors to become explicit. From the perspective of the assessed, the role-play was critically appraised. Some participants believed that it poorly reflected their authentic professional behaviors, and that they underperformed in the PA context.

"It was hard to perform a clinical examination or treatment in this setting; partly, because the patient is a colleague. It is not like in your own working room. In addition, you consciously think about the decisions you make, because your steps will be evaluated." (Q-P8)

\section{General learning outcomes}

The PA program resulted in distinct levels of selfreported behavioral change. Although participants studied the updated guidelines prior to the program and were tested on their knowledge with clinical vignettes, they reported that applying knowledge in the context of PA increased their understanding of the guidelines, and facilitated their use in clinical practice.
"Yes, you want to work according to the guidelines. Therefore, you need to master them...I realized that I in fact did not fully understand the guidelines for low back pain. I knew vaguely what the content was, but not exactly. I think I have obtained a better understanding of the classification system of patient profiles, and therefore I apply them more frequently in my work." (IT-P18)

Participants noticed that working with the guidelines in the context of the PA program changed their attitudes towards the guidelines. In their view, guidelines are often considered as too theoretical and of limited applicability in daily practice.

"I also noticed that some colleagues perceived the guidelines as less annoying or boring." (IT-P18)

Although participants did not explicitly report changes in their management of patient problems, they did report changes in their professional identity and awareness of the limitations of their profession.

"What clearly emerged from the cases we discussed [in the PA program] was that as a PT we like to help people and it remains questionable if that is always justified? We somehow suffer from an irrepressible desire to help....we're inclined to always give care, whereas in some cases restraint would be better." (IT-P14)

\section{Performing the PT role}

\section{Performing the clinical task individually}

Although some participants initially felt reluctant to move out of their "comfort zone", they considered exposure of their routine practice as a necessity for quality improvement. They pointed out that the four PA 
Table 5 Summary of results qualitative analysis PA Program tasks and Perceptions of the PA subtasks program

Determinants of PA Facilitators for learning and change
affecting

perceptions

Learning Processes Learning Outcomes

PA Program

hange in attitudes toward guidelines.

Awareness of professional limitations.

1 Study manual

2 Perform task in PT role

Fear to expose professional Tight time schedule. Training in the PT role. competence.

Challenge of obtaining
performance feedback.

Role play format.

Group safety

Receive peer feedback

4 Receive simulated patient feedback

5 Receive external coach feedback

6 Receive written feedback and scores

7 Observe peer performance

8 Provide oral feedback

9 Provide written feedback and scores

10 Design change plan

11 Perform task in Simulated patient role
Peer feedback is concrete, concise, critical and personal.

Varied group composition

External coach poses challenging questions,

guides the PA process, facilitates giving and

receiving feedback, provides non-judgmental,

concise feedback, monitors the time schedule maintains group safety.

Modeling peer performance.

Training in the assessor role.
Uncovers weakness.

Reinforces strength

Stimulates reasoning aloud,

self-assessment and critical reflection.

Reveals strength and weakness in clinical Improved self-efficacy beliefs performance.

Shows improvement areas. Reveals new reasoning perspectives and performance alternatives.

Stimulates self-assessment and critical reflection.

Reveals how interventions are perceived from the patient perspective.

Reveals new reasoning perspectives and performance alternatives.

Stimulates self-assessment and critical reflection.

Stimulates self-assessment and critical reflection.

Reveals new reasoning perspectives and Improved self-confidence in performance alternatives.

managing LBP patients.

Triggers being concrete and concise in Shared quality standards of reasoning aloud.

performance.

Awareness of gaps in

professional performance.

Improved self-confidence in arguing for choices.

in managing $L B P^{a}$ patients.

Elicits discussion over criteria. 
sessions allowed them to cope with anxiety triggers by training in the PT role.

"Yes, but you need to push yourself sometimes. I mean...I think it's threatening, it's not pleasant at all......but I also know that it is important to bare your buttocks, and look where you go wrong. No pain no gain, that's a bit of the rationale."(IT-P15)

Performance in the PT role necessitated reasoning aloud, triggered underpinning clinical decisions, and stimulated the transfer of research evidence to the context of a particular clinical problem. Participants explained that arguing aloud resulted in improved selfconfidence in decision-making. They became more aware of their strengths and weaknesses, either by "reflection in action" or by "reflection on action".

Exposing professional performance in the PT role was facilitated by perceived group safety.

"Your colleagues are the people who know you well and who know what your strengths and your weaknesses are. So they may well shoot at you." (IT-P18)

\section{Receiving peer feedback}

Although PTs organized in communities of practice discuss clinical cases on a regular basis, they do not have a culture of asking for and providing performance feedback. The opportunity to receive peer feedback was therefore embraced. Participants felt strengthened in areas of clinical performance they mastered, and felt challenged to appraise areas that needed improvement.

"Receiving peer feedback clearly revealed my strengths and weaknesses. I immediately understood what I needed to work on. And because my strengths were noticed, it was easier to face my weaknesses." (Q-P7)

Learning from peer feedback was facilitated by its quality. Participants preferred personalized feedback, that showed involvement with their development process and their personal learning needs, but feedback should also focused.

"I don't mind when someone criticizes me.... of course I like to know if I'm doing right, but I'd rather know what I can improve, and how."(IT-P18)

Another facilitating factor was the heterogeneity in group composition. Differences in age and specialization allowed for different approaches to health problems and different models of reasoning. Because feedback providers were encouraged to clarify improvement feedback with clear examples of desired behavior, they discovered new reasoning perspectives and performance alternatives.

"For example, we have a specialist in haptonomy in our team, and he brings in new perspectives on health problems....I profit from his views in my daily practice. For example, I try to keep the global overview instead of focusing on a single vertebra. As a manual therapist I tend to focus on the details and lose the whole picture." (IT-P14)

\section{Receiving external coach feedback}

In contrast to peer feedback, participants attributed the value of coach feedback to its objectivity, conciseness, and perceptiveness, rather than to its involvement with individual peers.

"Well, the coach had an objective approach. The feedback was very practical and well summarized. Nothing more, nothing less and because the coach was new, feedback was perceived to be more objective. I also noticed that the coach was able to discover strengths in all participants." (IT-P2)

However, from the PT-role perspective, the presence of the coach raised performance stress in some cases.

"We also needed to get used to her [coach]. At least, that applied to me. You need to feel a kind of safety with each other to show openly what you think and what you do. We share this safety in our group, and that allows us not to mince words. But with a strange person here, the threshold is higher, at least in my opinion".(IT-P1)

Facilitating behaviors from the coach included posing critical questions rather than giving straightforward answers, fostering a safe learning environment, monitoring the structure and the time-schedule of the PA process, facilitating peer feedback delivery, and strengthening group learning. Participants rejected too much interference of the coach and judgmental coach feedback.

\section{Receiving simulated patient feedback}

Participants varied in their appreciation of simulated patient feedback, referring to the limitations of role-play. Despite its limitations, participants valued the different perspective of patient feedback.

"While performing the assignment, I noticed that I was not always providing clear information...I previously never thought about that ...I have learned now that I 
need to communicate more carefully, for instance when giving bad news." (Q-P12).

\section{Performing the assessor role Observing a peer's performance}

Participants reported that the role of assessor allowed them to mirror and model the observed performance to their own intended performance.

\section{"I found observing a peer's performance very instructive because you often imagine how you would handle the situation. When you see how your colleague deals with a problem, you critically reflect on your own choices." (Q-P19)}

Appraising the performance of a peer was not a common practice. Participants would rather discuss than assess the observed behaviors. Giving instructive feedback (according to the feedback guidelines) was perceived as difficult. It required clear reasoning strategies, arguing for quality standards of performance, and the courage to be critical.

"Your own feedback should be carefully considered. You must clearly explain why you do or don't agree with the feedback of your colleagues." (Q-P20)

\section{Discussion}

This study aimed to explore the critical features of a PA program that was shown to be effective in a previously published randomized controlled trial. The results clearly show that participants committed the most to learning tasks related to performance in the therapist role: performing the task, receiving peer feedback, external coach feedback, and simulated patient feedback. Participants varied widely in the perceived learning value of subtasks related to performing the PT role, but agreed on the superior value of receiving peer feedback. In the next section, we will elaborate on these results.

These results point to the importance of exposing observable behavior (PA) rather than expressing intended behavior (Case Discussion). Although exposure was associated with feelings of discomfort and performance stress, its impact on awareness of professional development was not questioned. This raises the question of how feelings of discomfort and stress can affect learning and change in professional practice.

In the PT role, participants needed to make the transfer from implicit reasoning to explicit reasoning and from intentional behavior to observable behavior to allow for assessment and feedback. Bandura's social cognitive theory emphasizes that exposure is conditional to the development of mastery experiences, and mastery experiences are the most important source of information for the development of self-efficacy beliefs. In turn, self-efficacy beliefs contribute significantly to performance improvement and motivation to change [33]. This notion is supported by the theory of planned behavior [34]. Bandura also points to the importance of the peer group in strengthening self-confidence through "vicarious" experiences provided by social models. The impact of modeling on perceived self-efficacy is strongly influenced by perceived similarity to the models (peers) and is considered to be more powerful than performance feedback [35]. Increased self-confidence might have helped participants to approach difficult tasks as challenges to be mastered rather than as threats to be avoided.

The foregoing explains how PA participants succeeded in raising self-efficacy beliefs despite feelings of performance stress, but does not explain why they showed superior test results on clinical vignettes in the trial (Table 1). High arousal levels are generally considered to have a negative impact on the quality of performance according to the Yerkes-Dodson law [36], and PA participants' experiences supported that, as they contended that they had underperformed in the PA context. However, they must have processed the information in a way that enhanced retrieval and transfer of knowledge to the context of clinical vignettes. Studies addressing the influence of emotion on cognitive processing provide an explanation for this apparent contradiction. McConnel \& Eva [37] conducted a literature review on the impact of emotion on the transfer of clinical knowledge and skills. They conceptualized emotion by two dimensions: valence and arousal. Valence refers to the emotional state (e.g. positive or negative). Arousal refers to the level of activation. One of the findings was that emotional experiences are more likely to be mulled over than non-emotional experiences. This unintentional retrieval of emotional events might have strengthened memory traces of PA participants and facilitated the transfer to new clinical problems. Another view is presented by regulatory focus theory [38], which contends that receptiveness to feedback depends on "emotional arousal" rather than "emotional valence". Summarizing these considerations, the critical feature of PA might be attributed to the emotional involvement (either negative or positive) with performing the PT role. As feelings of failure do not contribute to the development of self-efficacy beliefs [33], successful PA implementation should allow for coping with performance stress within or between the sessions. Training in the PT role and a safe learning environment might be crucial to enable the coping process.

Performance in the assessor role was perceived as a less powerful learning experience. However, it should be noted that the assessor role and the PT role cannot be 
considered as independent. Observing peer performance allowed observers to model the observed behavior, which might have contributed to reducing performance stress and triggering performance improvement. On a more unconscious level, participants might have profited from the activity of the mirror neuron system [39] that is capable of shaping the observed behavior to a virtual image of their intended behavior. In appraising their peers' performance, assessors needed to reason aloud, compare personal views with group views, and discuss performance standards. This may have provided peer assessors with the missing data for informed self-assessment [20].

Regarding the role of the external coach in providing feedback, participants ranked peer feedback higher than coach feedback although coach feedback was valued because of its objectivity, its conciseness, and its receptiveness. A comparable study on peer assessment in undergraduate PT education, in which students were asked to rank similar learning tasks, showed that students preferred teacher feedback to peer feedback [17]. Professionals did not question the quality of peer feedback compared to coach feedback, but emphasized the importance of peers being involved in their professional development process. This finding is supported by situated learning theory [40, 41], which contends that the transfer of knowledge is hampered by the gap between the learning context and application context. Delivering the implementation program within communities of practice allows for co-constructing and tailoring knowledge to the personal learning needs [41]. In this respect, the coach remained an outsider.

Although the PA program was successful regarding its aim, the adoption of the program for knowledge transfer purposes should be carefully considered.

Firstly, some participants argued that the role-play format did not adequately reflect their authentic professional behaviors. This view is understandable, but compared to passive guideline dissemination, role-play aims to facilitate the transfer of scientific evidence to clinical practice, which it did, according to participant reports. As regards the use of peer role-play (low fidelity simulation) compared to standardized patients (high fidelity simulation), research in undergraduate education shows that both tools provide a psychological safe area of practice, where mistakes are not critical [42]. Studies on student perceptions show that standardized patients are perceived as more effective than peers $[43,44]$. However, research evidence on learning outcomes remains inconclusive [44, 45]. Compared to direct observation (work-place based assessment), the role-play format allows for standardizing the content of interest, creating an adequate case mix, and describing the key-features of health problems relevant to the guidelines, [46]. Considering constraints in time and costs, peer role-play is the most feasible method. This conclusion is supported by a systematic review undertaken by Overheem et al. [47], who evaluated the feasibility and effectiveness of six methods to assess physician performance.

Secondly, some participants perceived the tight time schedule as stressing and preventing in-depth elaboration of the clinical problems. The PA program was designed to enhance the transfer from the learning context to the application context, as the transfer from one problem to another problem [48]. Yet, in an attempt to solve all the presented problems within time limits, the approach to learning might have been too superficial.

Thirdly, performance in the PT role was perceived as challenging and sometimes even threatening. When conditions of psychological safety are not met, the effectiveness of PA might be questioned [14].

\section{Strengths and limitations}

This study provided rich data and convincing results. Because we clearly described the program design, its underlying theoretical constructs, and the critical features of successful guideline implementation, future program designers may profit from our results.

It can be argued that a limitation of the PA approach is the role-play of peers simulating patients. Although the choice of peers instead of standardized patients was defensible as argued above, and although the results show that their feedback was valued, additional training in the patient role might have increased the fidelity of the peers' performance.

Another limitation concerns the questionnaire and the interview guide. Questionnaire comments were reduced by the three tasks with the highest-ranking results. We compensated for this limitation by interviewing participants with contrasting ranking results. Nevertheless, because we did not focus on less instructive tasks in our interviews, we might have lost information that would have underpinned our results.

Finally, the generalizability of our results might be limited because all participants in this study were Dutch. Research shows that effective peer assessment practices are culture dependent $[23,24]$.

\section{Conclusions}

The effectiveness of PA can be attributed to the structured and performance-based design of the program. Participants showed a strong cognitive and emotional commitment to performing the tasks related to the physical therapist role. That might have contributed to an increased awareness of strengths and weaknesses, and a motivation to change routine practice in the management of patients with low back pain.

Conditional to successful implementation is an environment where mistakes can easily be made, but in which 
the self-confidence of participants remains undamaged. Adjustment of the tight time schedule and the number of cases, providing more time to elaborate on problems and to recuperate from experiences, might improve the PA task design. However, attempts to improve the effectiveness of PA should not be limited to the modification of the PA tool. We recommend a shift in the feedback culture of PTs in primary care, from avoiding performance feedback to actively seeking feedback.

Future research should address the feasibility of PA as a tool to enhance bottom-up quality improvement and accountability to external stakeholders of PT care.

\section{Additional files}

Additional file 1: Online questionnaire. (PDF $213 \mathrm{~kb}$ )

Additional file 2: Interview guide. (PDF $317 \mathrm{~kb}$ )

\section{Competing interests}

All authors declare that there are no competing interests.

\section{Authors' contributions}

All authors read the final manuscript, gave their approval for publication, and agreed to be accountable for all aspects of the work. MM and PW contributed to study conception and design, sampling, analysis and interpretation of data, drafting and revision of the manuscript. SD, MS and YH contributed to data analysis, interpretation, and revision of the manuscript. MN and CV contributed to study conception, design, and revision of the manuscript.

\section{Acknowledgements}

This study was a researcher initiated study, primarily funded by the Royal Dutch Society for Physical Therapists (KNGF) and co-funded by the Radboud Institute for Health Sciences, Scientific Institute for Quality of Healthcare and the HAN University of Applied Sciences. The KNGF had no role in the conduct of this study, analysis or interpretation of data.

We thank all participating PTs in this study, Henk van Enck (HE) for his contribution as external coach, and Angelique Schlieff (AS) and Gosse Bootsma (GB) for their assistance in conducting the interviews.

\section{Author details \\ ${ }^{1}$ HAN University of Applied Sciences, Institute for Health Studies, Kapittelweg 33, 5425 EN Nijmegen, The Netherlands. ${ }^{2}$ Radboud University Medical Center, Institute for Health Sciences, IQ healthcare, Geert Grooteplein 21, 6525 EZ Nijmegen, The Netherlands. ${ }^{3}$ Radboud University Medical Center Department of Primary and Community Care, Nijmegen, The Netherlands. ${ }^{4}$ Dutch Institute of Allied Health Care, Amersfoort, The Netherlands. ${ }^{5}$ Maastricht University, Department of Educational Development and Research, Faculty of Health, Medicine and Life Sciences, Maastricht, The Netherlands.}

Received: 24 April 2015 Accepted: 3 November 2015

Published online: 12 November 2015

\section{References}

1. Grol RP, Wensing M, Eccles MP, Davis DA. Improving Patient Care: The Implementation of Change in Health Care. 2nd ed. Chichester: WileyBlackwell; 2013.

2. Van der Wees PJ, Moore AP, Powers CM, Stewart A, Nijhuis-van der Sanden MWG, de Bie RA. Development of clinical guidelines in physical therapy: perspective for international collaboration. Phys Ther. 2011;91:1551-63.

3. Bekkering GE, Van Tulder MW, Hendriks EJ, Koopmanschap MA, Knol DL, Bouter LM, et al. Implementation of clinical guidelines on physical therapy for patients with low back pain : randomized trial comparing patient outcomes after a standard and active implementation strategy. Phys Ther. 2005;85:544-55.
4. Bekkering GE, Hendriks EJ, van Tulder MW, Knol DL, Hoeijenbos M, Oostendorp RA, et al. Effect on the process of care of an active strategy to implement clinical guidelines on physiotherapy for low back pain: a cluster randomised controlled trial. Qual Saf Health Care. 2005;14:107-12.

5. Van der Wees PJ, Jamtvedt G, Rebbeck T, de Bie RA, Dekker J, Hendriks H. Multifaceted strategies may increase implementation of physiotherapy clinical guidelines: a systematic review. Aust J Physiother. 2008;54:233-41.

6. Harting J, Ruttten GM, Rutten ST, Kremers SP. A qualitative application of the diffusion of innovations theory to examine determinants of guideline adhrence among physical therapists. Physic. 2009;89:221-32.

7. Van Bodegom-Vos L, Verhoef J, Dickmann M, Kleijn M, van Vliet I, Hurkmans E, et al. A qualitative study of barriers to the implementation of a rheumatoid arthritis guideline among generalist and specialist physical therapists. Phys Ther. 2012;92:1292-305.

8. Dannapfel P, Peolsson A, Nilsen P. What supports physiotherapists' use of research in clinical practice? A qualitative study in Sweden. Implement Sci. 2013;8:31.

9. Rutten GM, Kremers S, Rutten ST, Harting J. A theory-based cross-sectional survey demonstrated the important role of awareness in guideline implementation. J Clin Epidemiol. 2009;62:167-76.

10. Epstein RM. Self monitoring in clinical practice. J Contin Educ Health Prof. 2008;28(1):5-13.

11. Davis DA, Mazmanian PE, Fordis M, Van HR, Thorpe KE, Perrier L. Accuracy of physician self-assessment compared with observed measures of competence. A systematic review. JAMA. 2006;296:1094-102.

12. Eva KW, Regehr G. "I ' || mever play professional football " and other fallacies of self-assessment. J Contin Educ Health Prof. 2008;28:14-9.

13. Sargeant J, Eva KW, Armson H, Chesluk B, Dornan T, Holmboe E, et al. Features of assessment learners use to make informed self-assessments of clinical performance. Med Educ. 2011;45:636-47.

14. Eva KW, Armson H, Holmboe E, Lockyer J, Loney E, Mann KV, et al. Factors influencing responsiveness to feedback: on the interplay between fear, confidence, and reasoning processes. Adv Health Sci Educ Theory Pract. 2012;17:15-26.

15. Mann K, van der Vleuten CP, Eva KW, Armson H, Chesluk B, Dornan T, et al Tensions in informed self-assessment: how the desire for feedback and reticence to collect and use it can conflict. Acad Med. 2011;86:1120-7.

16. Baker R, Camosso-Stefinovic J, Gillies C, Shaw E, Chetaer F, Flottorp S, Robertson N. Tailored interventions to overcome identified barriers to change: effects on professional practice and health care outcomes. Cochrane Database Syst Rev. 2010;3

17. Maas MJM, Sluijsmans DM, van der Wees PJ, Heerkens YF, Nijhuis-van der Sanden MWG, van der Vleuten CPM. Why peer assessment helps to improve clinical performance in undergraduate physical therapy education: a mixed methods design. BMC Med Educ. 2014;14:117.

18. Van Dulmen SA, Maas MJ, Staal B, Kiers HJ, Bie RA, Van der Wees PJ, et al. Effectiveness of peer-assessment for implementing a Dutch physical therapy low back pain guideline: a cluster randomized controlled trial. Phys Ther 2014:94:1396-409.

19. Mann K, Gordon J, MacLeod A. Reflection and reflective practice in health professions education: a systematic review. Adv Health Sci Educ Theory Pract. 2009;14:595-621.

20. Epstein RM, Siegel DJ, Silberman J. Self-monitoring in clinical practice: a challenge for medical educators. J Contin Educ Health Prof. 2008;28:5-13.

21. Pronovost PJ, Hudson DW. Improving healthcare quality through organisational peer-to-peer assessment: lessons from the nuclear power industry. BMJ Qual Saf. 2012;21:872-5.

22. Ramsey PG, Wenrich MD, Carline JD, Inui TS, Larson EB, LoGerfo JP. Use of peer ratings to evaluate physician performance. JAMA. 1993;269:1655-60.

23. Lin SSJ, Liu EZF, Yuan SM. Web-based peer assessment : feedback for students with various thinking-styles. J Comput Assist Learn. 2001;17:420-32.

24. Topping KJ. Methodological quandaries in studying process and outcomes in peer assessment. Learn Instr. 2010;20:339-43.

25. Brehaut JC, Eva KW. Building theories of knowledge translation interventions: use the entire menu of constructs. Implement Sci. 2012;7:114.

26. Colquhoun HL, Brehaut JC, Sales A, Ivers N, Grimshaw J, Michie S, et al. A systematic review of the use of theory in randomized controlled trials of audit and feedback. Implement Sci. 2013;8:66.

27. Ivers NM, Sales A, Colquhoun H, Michie S, Foy R, Francis JJ, et al. No more "business as usual" with audit and feedback interventions: towards an agenda for a reinvigorated intervention. Implement Sci. 2014;9:14. 
28. KNGF Richtlijn Lage-Rugpijn voor fysiotherapie en manuele therapie [Guideline low back pain for physical therapy and manual therapy]. [http://www.fysionet-evidencebased.nl/index.php/component/kngf/ richtlijnen]Accessed 6 Jul 2014.

29. Janssen-Noordman AMB, Merriënboer JJG, van der Vleuten CPM, Scherpbier AJJA. Design of integrated practice for learning professional competences. Med Teach. 2006;28:447-52.

30. King N, Cassel C, Symon G. Using templates in the thematic analysis of texts. In: Essent Guid to Qual methods Organ Res. Edited by Cassell C, Symon G. 1st ed. London: Sage Publications; 2004. p. 256-70.

31. Huberman AM, Miles MB, Denzin NK, Lincoln YS. Data management and analysis methods. In: Handb Qual Res. Edited by Denzin NK, Lincoln YS. London: Sage Publications; 1994:p. 428-444

32. Qualitative research review guidelines - RATS. [http://www.biomedcentral. com/authors/rats]Accessed 10 Sep 2014

33. Bandura A, Locke EA. Negative self-efficacy and goal effects revisited. J Appl Psychol. 2003:88:87-99.

34. Ajzen I. Nature and operation of attitudes. Annu Rev Psychol. 2001;52:27-58.

35. Usher EL, Pajares F. Sources of self-efficacy in school: critical review of the literature and future directions. Rev Educ Res. 2008;78:751-96.

36. Teigen K. Yerkes-Dodson: a law for all seasons. Theory Psychol. 1994:4:525-47.

37. McConnell MM, Eva KW. The role of emotion in the learning and transfer of clinical skills and knowledge. Acad Med. 2012;87:1316-22.

38. Higgins TE. Beyond pleasure and pain. Am Psychol. 1997;52:1280-300.

39. lacoboni M. Mirroring People: The New Science of How We Connect with Others. 2nd ed. New York: Macmillan; 2009.

40. Lave J, Wenger E. Communities of practice. 1998

41. Li LC, Grimshaw JM, Nielsen C, Judd M, Coyte PC, Graham ID. Evolution of Wenger's concept of community of practice. Implement Sci. 2009:4:11.

42. McCaghie WC, Issenberg BS, Petrusa ER, Scalese RJ. A critical review of simulation-based medical education research: 2003-2009. Med Educ. 2010:44:50-63.

43. Munshi F, Lababidi H, Alyousef S. Low- versus high-fidelity simulations in teaching and assessing clinical skills. J Taibah Univ Med Sci. 2015;10:12-5.

44. Bosse HM, Nickel M, Huwendiek S, Jünger J, Schultz JH, Nikendei C. Peer role-play and standardised patients in communication training: a comparative study on the student perspective on acceptability, realism, and perceived effect. BMC Med Educ. 2010;10:27.

45. Mounsey AL, Bovbjerg V, White L, Gazewoord J. Do students develop better motivational interviewing skills through role-play with standardised patients or with student colleagues? Med Educ. 2006;40:775-80.

46. Farmer EA, Page G. A practical guide to assessing clinical decision-making skills using the key features approach. Med Educ. 2005;39:1188-94.

47. Overheem K, Faber MJ, Onyebuchi AA, Elwyn G, Lombarts KM, Wollersheim $\mathrm{HC}$, et al. Doctor performance assessment development in daily practise: does it help doctors or not? A systematic review. and impact of a new system. Med Educ. 2007;41:1039-49.

48. Norman G, Bordage G, Page G, Keane D. How specific is case specificity? Med Educ. 2006;40:618-23.

49. Grant AM, Franklin J, Langford P. The self-reflection and insight scale: a new measure of private self-consciousness. Soc Behav Pers. 2002;30:821-36.

50. Schön D. The Reflective Practitioner: How Professionals Think in Action. San Francisco: Jossey-Bass Inc; 1983.

51. Greene J, Azevedo R. A theoretical review of Winne and Hadwin's model of self-regulated learning: new perspectives and directions. Rev Educ Res. 2007;77:334-72

52. Li LC, Grimshaw JM, Nielsen C, Judd M, Coyte PC, Graham ID. Use of communities of practice in business and health care sectors: a systematic review. Implement Sci. 2009;4:27.

53. Prochaska JO, Redding CA, Evers KE. The transtheoretical model and stages of change. In: Heal Behav Heal Educ Theory, Res Pract. 4th edition. Edited by Glanz K, Rimer BK, Viswanath K. San Francisco: Wiley \& Sons; 2008:p. 97-121.

\section{Submit your next manuscript to BioMed Central and take full advantage of:}

- Convenient online submission

- Thorough peer review

- No space constraints or color figure charges

- Immediate publication on acceptance

- Inclusion in PubMed, CAS, Scopus and Google Scholar

- Research which is freely available for redistribution

Submit your manuscript at www.biomedcentral.com/submit 